PART 2

THE AUTO/ETHNOGRAPHIC IMAGINATION 


\title{
6. DOING ETHNOGRAPHIC RESEARCH IN ADULT EDUCATION
}

\author{
Reflections on Studying Citizenship in a Study Circle
}

\section{INTRODUCTION}

The aim of this chapter is to reflect on and discuss ethnographic methodology, specifically within adult education research, exemplified with a study in a non-formal adult education setting. Examples are taken from a participatory ethnographic field study in an English as a foreign language study circle, which took place within an institution of Nordic popular education.

The roots of ethnographic research are found in anthropology but is now carried out in a variety of fields. Ethnography is an ambiguous term with diverse meanings which can broadly refer to qualitative approaches to social research such as case study, life history or qualitative research in general (Hammersley \& Atkinson, 2007; Pole \& Morrison, 2003). Further, ethnography can be used as both a noun and a verb. In other words, ethnography refers to both research as activity and the result or product of the undertaken research (Pole \& Morrison, 2003). It is also important to consider that ethnography can be understood as a set of research methods and as a methodological stance (Brewer, 2000; Pole \& Morrison, 2003). In this chapter, we discuss ethnography primarily as the latter but believe that the philosophical considerations of research cannot be fully separated from methodological considerations (Brewer, 2000).

We define ethnography as a methodology for studying people in particular cultural and social settings, often referred to as "fields" (Brewer, 2000, p. 6) in order to understand the meanings of everyday life, experienced at first hand (Pole \& Morrison, 2003, p. 3; Geertz, 1973; Davies, 2002). The researcher participates in the setting and to a lesser or greater extent also takes part in the on-going activities there (Brewer, 2000, p. 6). We see the value in this kind of research in its potential to understand the surrounding culture we are embedded in and how this is linked education and human growth in general (Weisner, 1996). We argue there is value to research that is trying to capture the core of socially and societally aware adult education - namely active, democratic participation. This reflects commitment to democratic processes, respecting the input of the participants and attempting to put the participants' view at the forefront, before theoretically informed questions and 
interests. This is perhaps especially true for non-formal forms of adult education, such as study circles, which are meant to be open-ended forms of studying and learning.

The chapter reflects on the process of doing ethnographic research in educational settings in the following manner. First, we give a brief overview of our research and the planning and design of the study. We then move on to discuss the fieldwork, dealing with key questions in ethnographic research of gaining access to the field, building trust, and leaving the field. In the following sections we highlight the role of the ethnographer and the role of fieldnotes as well as the analytical process with attention to the use of theory.

\section{SETTING THE SCENE: CHOOSING ETHNOGRAPHY}

The example study discussed below (Pastuhov \& Rusk, 2017) was the third and final of ethnographic studies in study circle settings undertaken for a $\mathrm{PhD}$ thesis (Pastuhov, 2018). The aim of the research was to investigate the relation between the ideals and practices in study circles in Nordic popular education. The aim was to shed light on if and how the participants view citizenship in and through their participation in an English as a foreign language study circle (Pastuhov \& Rusk, 2017).

Nordic popular education seeks to enhance societal participation and strengthen grassroots democracy (Laginder, Nordvall, \& Crowther, 2013; Larsson, 2001; Tøsse, 2009). Popular education strives to make knowledge accessible to people through practices that allow participants to influence the organization of the studies by, for example, taking participants' previous experience into account (Harding, 2011; Laginder, Nordvall, \& Crowther, 2013). Even though Nordic popular education is informed by democratic ideals, not many studies have focused on the democratic practices during the study activities. A significant number of previous studies have focused on popular education as a concept, as well as its ideals, aims and uniqueness (Tøsse, 2009). There are also prior studies highlighting the participants' perspective, but most of these consist of surveys or interview studies (e.g. Andersson \& Laginder, 2013). This identified gap in the research informed the choice of ethnography as a methodology.

The research looked specifically at study circles organized and supported by study associations (in Swedish 'studieförbund') (Larsson \& Nordvall, 2010). Study circles are an important part of Swedish 'popular education', which consists of statesubsidized non-formal and often non-accredited education. These circles consist of small groups gathering on a regular basis to study a topic of their own interest. There is a high level of participation in popular education: in 2017, 624000 participants took part in these organized study circles (Folkbildningsrådet, 2018), approximately $8 \%$ of the adult population (SCB, 2018). 


\section{FIELDWORK ON THE STUDY CIRCLE}

In our study, participant observation was the main research method. As is customary (Pole \& Morrison, 2003), the fieldwork was combined with some secondary data in this case an interview with the study circle leader and an analysis of brochures from the study association. For us good fieldwork requires a balance, on one hand, between openness to discoveries in the field and, on the other hand, a systematic approach to collecting data (Brewer, 2000; Geertz, 1973), mainly through the writing of fieldnotes. In the following, we want to highlight and discuss this balancing act in getting access and then gaining and building trust and eventually leaving the field. In discussing the practical aspects of doing fieldwork from here onwards, we will be using the first person, since only one of us (Annika) conducted the fieldwork.

\section{Access to the Field}

Doing ethnography means working collaboratively with people. As a part of this process, accessing the field is often portrayed as a crucial and also demanding phase (Hammersley \& Atkinson, 2007) which, in Geertz's (1973, p. 13) words is all about "finding our feet". This balancing act should neither end up with the researcher becoming one of participants, nor seeking to mimic them. The aim is, in all its simplicity and complexity, to converse with the participants.

Accessing the English language study circle happened with the help of the director of the study association. I met to discuss my research interests and possible sites. I was open at this stage to any suggestions from the director. A guiding principle was to identify a circle with a leader who would not be bothered by my participation as the study circle leader would most likely influence how the participants would respond. The meeting with the study circle was also preceded by e-mail contact with the teacher. The director and the teacher functioned as gatekeepers (see Hammersley \& Atkinson, 2007), and their support was pivotal. In this case, the teacher would prove to be especially influential.

The aim was to attend a whole course in order to understand the learning culture in detail and avoid misinterpretations based on lack of insight into the whole cycle of the course (compare Hammersley \& Atkinson, 2007, p. 52). In this case, there were quite clear beginning and end to the study circle - it stretched from early September to late November.

When entering the study circle, I had asked to have a few minutes to introduce myself and to give a brief overview of the research interest and my focus on the collective aspects of participation and its impact on citizenship. The participants were informed that the notes and recordings from these sessions would only be used for these research purposes, that they would remain anonymous in the reporting of the study and that any hesitations regarding participation in the study could be voiced then or later to either the study circle leader or me. The idea of a researcher 
entering the group was not met with any strong reactions. Rather, this news was met with silence and no direct show of emotions, which made my first attempts at conversation with the group quite difficult. Finally, one of the participants asked: "What will your participation help you accomplish?" I tried to answer, as briefly but as thoroughly as possible, that my interest concerned what it was like to be part of this study circle and what it was like to be a participant. It was hard to tell if this answer was understandable or incomprehensively vague. There were no follow-up questions however, and the teacher then asked us to draw attention to the first task. Apparently, I had now become part of the group, at least to some extent.

\section{Gaining Trust}

In order to become a participant observer and be able to understand what is going on in the everyday life of the studied context, the task at hand is to find a place in the group. In the end, this is a question about establishing oneself as trustworthy in the eyes of the participants. This is not just a pragmatic question, but also a question of respect towards the participants. Trust is something that can only be built over time.

Quite early into the fieldwork the other participants started to position me as different because my knowledge of English was more comprehensive. I could for example observe how most of the group would be especially attentive during verbal exercises when I was speaking. As time went by, some participants started to ask me to help them from time to time. When asked a direct question of this kind, it felt only right to respond to it in a helpful way. At the same time, I tried to navigate the situation and keep a low profile and avoid taking on a role as a co-teacher.

My main concern throughout the research was whether I had been able to communicate effectively with the other participants regarding both my research interests and their participation. Some of the participants repeatedly voiced an inability to understand my interest in the participatory and social dimensions of the study circle group. Because of this, I asked to give a small presentation at the end of a session in the middle of the autumn. I talked about how I had found our way of working to be quite school-like, that there was tangible motivation for the studies, and that there was always something to laugh about together during our evenings. The participants listened attentively, and I got a couple of questions about how I viewed their participation in relation to citizenship and what I was about to do with my material. In my answer, I pointed to learning languages as a opportunity to be part of new communities. I also told them I was about to write an article of my experiences in the group. Possibly, this made something clearer for some of the participants, but I was not convinced this broke the invisible walls between us.

As the fall went by, I was still not completely satisfied with my communication with the participants. Since the day-to-day activities in the group were quite taskoriented and lacked informal socializing, I decided towards the end of the semester, to try and complement the participatory observations with some focus group interviews. When asked in late autumn to participate in a group interview about their 
studies, the participants responded mostly with silence. Some talked about a lack of time. Unfortunately, since there was no interest in participating, no focus group interviews were conducted. This raised doubts in me: Do I not appear trustworthy enough to be given an hour of their time? Could I have done something differently?

\section{Leaving the Field}

As the fieldwork came to an end, my focus shifted to the production of the ethnographic report. An important part of ethnographic fieldwork is to actually leave the field in order to deepen the analysis.

Leaving the English study circle did not take any particular effort since the study circle came to an end by itself in late November. I continued to worry about the participants' hesitancy. With this in mind, and as a sign of general appreciation, I brought gingerbreads and chocolate to the last gathering of the study circle. The beginning and end of the last session goes to illustrate, that the lingering feeling of not really being on the same wavelength was something that I never was able to fully solve. The slight indifference of the participants towards my gesture in the beginning of the session was striking. A bit astounded by the continuing difficulty of grasping sentiments in the group, I finally asked in the end of the last session, if anybody had felt any unease with my participation. No one responded with anything distinct. I then went on to ask if I had bothered anybody with my presence. To my relief, several participants replied quite sincerely 'not at all'.

When the last session came to an end, I thought someone would come up and talk to me or that participants would exchange some final goodbyes or greetings for the upcoming holidays. On the contrary, I stood around, feeling a little foolish, witnessing how the other participants hurried to get their coats and move on to the rest of their possible commitments for the evening. There really was no 'leaving' the field but rather a sense of the 'field' evaporating in front of my eyes.

The balancing act between ethnographic openness and a systematic ambition turned out to be quite unsettling. There are always things that could have been said and done differently. In the end, the fieldnotes and recordings, combined with sentiments and memories from the fieldwork allowed me reflect on and analyze what was going on as a whole and from a certain distance.

\section{REFLECTIONS ON THE ANALYTICAL PROCESS}

The foundation of an ethnographic analysis is mainly laid during the fieldwork. The ethnographer will focus attention on some aspects of what is going on and not for others. Observing what it is to participate and study English together with my group, the research interest was eventually narrowed down.

The overall knowledge claim here is grounded on the aim of understanding the studied reality or culture in its own terms but from a specific perspective (Geertz, 1973). The interest of the interpretation is the lived culture in the field of study: 
What is going on in this setting? This is attempted from an inside perspective (Pole \& Morrison, 2003) and by mediating these findings into communicable terms (Emerson, Fretz, \& Shaw, 2001) - that is, by taking part in the activities as one of the participants, but in contrast to others, also writing down what happens. As an ethnographer, the researcher is inevitably involved in shaping the social processes studied. The ethnographic process is in other words creative, and the knowledge acquired is characterized by creativity and consideration (Sivenius \& Friman, 2017).

To highlight the analytical dimensions of doing ethnography - that is, ways ethnographies contribute with knowledge and what this knowledge consists of - we continue to discuss the role of the ethnographer, the role of fieldnotes and the role of theory.

\section{The Role of the Ethnographer}

To understand what is going on in the study circle, I needed to take part in the studied activities to develop acquaintance with the habits, norms, beliefs and desires of the participants in the study circle. Through the understanding of habits and beliefs, I had the possibility to understand the value of the social practices, even in cases when I was not able to fully accept these social presumptions. I was struck by the way the participants were complying with their exercises and not wanting to be part of a dialogue about how to carry out the studies. Why would anybody want to return to school-like studies as adults on a voluntary basis? It was also puzzling to me to discover how some of the participants referred to themselves in belittling ways calling themselves for example 'stupid'.

This called for a reflexive approach, in order to avoid simply mimicking the participants (Geertz, 1973). The intention of this reflexive approach can be summarized as the ambition of making the familiar unfamiliar and vice versa (Spindler, 1982), through systematization of the human day-to-day ways of understanding and creating meaning (Hammersley \& Atkinson, 2007). Through curiosity and openness to the perspectives of others, it is possible for the ethnographer to come to terms with previously unfamiliar experiences and motives.

My reflexive role as an ethnographer is of importance both for ethical considerations and for the meaningfulness and trustworthiness of the analysis. The main interest for me was to observe the studied practices broadly, trying to alternately search for specific paradoxes and problems, alternately for nothing in particular (compare Wolcott, 1981). When I took part in the activities in the study, I paid attention to being attentive and respecting the other participants, trying to imagine what it is like to be one of the others by immersing into the activities. The more distanced aspects of analysis came at play when reading the initial fieldnotes and expanding on the fieldnotes afterwards.

A possibility for exceeding my individual perspective and assumptions is to employ what can be called researcher triangulation (see Cohen, Manion, \& 
Morrison, 2002; May, 1993). In this case it meant that one of the researchers had been conducting the fieldwork and made initial reflections and analyses. The observations and impressions were then shared with another researcher who could provide new perspectives and also question certain ideas. Researcher triangulation proved to be fruitful in deepening the analysis, since it encouraged me as an ethnographer to reflect on my feelings of unease during the fieldwork. Looking at my observations in the field, a reflection was striking: perhaps there was no substantial group to be part of? After all, I could safely say, I had made several attempts at communicating my interest and trying to integrate into the group. Instead of looking at the fieldwork as a failure to some degree, this interaction with the participants can illustrate the underlying assumptions making the activities in the study circle possible.

\section{On Fieldnotes}

We view fieldnotes as an emerging dialogue between theory and practice. The more considered the verbal and conceptual descriptions become, the thicker the examination of the studied phenomenon can become. Thick descriptions are essentially analyses of webs of significance, that is, contextual significances spun by the actors, informants or hosts themselves (compare Geertz, 1973, pp. 5-7). Thick descriptions mean theoretically informed descriptions of a phenomenon at hand, with the intention of conceptualizing the phenomenon. The understanding and interpretations are aimed at the participants' interpretations of the situation and my interpretations are thus at least of a 'second order' (see for example Geertz, 1973, pp. 13-15, 20-21).

The analytic art of writing fieldnotes is, however, filled with complexity, since the fieldnotes cannot be separated from contexts (Geertz, 1973). Writing fieldnotes was quite easily accomplished in the classroom setting of the study circle, where writing was constantly occurring. There was in other words no risk of for example being viewed as totally off and strange when being seen writing notes, even been seen as suspicious (compare Emerson et al., 2001).

The class as an example of social practice functioned as a starting point for analyzing and understanding the study circle. This was informed by an initial surprise during the fieldwork about how meticulously the participants were taking notes and how conscientiously the given tasks were performed. Attending the first session, my fieldnotes convey, that "we are sitting in rows, pronouncing words", and that there is a certain "safety about filing out papers, copying given alternatives". A few weeks later the first comparison to school practices is made. In a concluding discussion, initiated jointly by the study circle leader and me, the notion of participation as "investment in oneself" was coined by one of the participants and seconded by the group. This quote was eventually used to summarize the type of social practice that was expressed in the study circle - to me a rather surprising conclusion to the fieldwork. 


\section{Focusing the Analysis: The Role of Theory}

In order to achieve a meaningful analysis, and eventually a meaningful ethnographic research report, understandable also for an outsider, we argue for the need of a conceptual framework for both theoretical and empirical understanding (compare Pole \& Morrison, 2003). The initial detailed descriptions - in our example of the study circles activities as school-like activities - are refined through an explorative analytical process to identify key concepts, with an interest in the complexities of the studied social endeavours (Hammersley \& Atkinson, 2007; Pole \& Morrison, 2003).

The point of departure of the ethnographic investigation, found in the day-today activities, the repetition and the mundane, is eventually combined with a more specific research interest. In our example, this interest was citizenship in a broad sense, comprising of taking part in activities and identification of some kind (compare for example Bagnall, 2010; Biesta, 2011). In order to focus on citizenship within the activities of a study circle, citizenship was understood to be constructed in and through actions within the study circle setting. Citizenship in this context takes place in social interactions where differences are encountered and private issues are translated into public concerns (Bauman, 1999; Biesta, 2011). The study circle could be presumed to influence the persons acting and participating there, and furthermore to influence public opinions and the formation of social bonds. In the English study circle, one tangible aspect of citizenship is the learning of a new language. Becoming more proficient in a language provides possibilities to understand and be part of new contexts. The ways these studies are carried out are thus interesting as an example of entering a public conversation in a broad sense. In our example, this entrance into the English language was characterized by an interest in adapting 'private issues'; complying with a set structure for the studies, rather than setting a shared agenda about what the group could have seen as shared 'public concerns'.

The earlier-mentioned participants' expressed understanding of their participation as taking individual responsibility was further elaborated in the analysis with the help of the theoretical considerations regarding citizenship. This opened up for a concluding discussion in the final version of the published article, highlighting the expressed individual stance "as limiting possibilities for responsibility and thus expressions of citizenship".

\section{CONCLUSIONS: ETHNOGRAPHIC RESEARCH AND KNOWLEDGE}

Ethnographic knowledge is interpretive. The contribution of an ethnographic description lies in its ability to clarify 'what goes on', making use of a microperspective to bring relevant order into what might seem confusing, or also too familiar. Ethnographic description is 'thick' and interpretive, concerns social discourses and attempts to preserve what is being said and done in communicable terms.

We regard this knowledge endeavour as critical in the sense that we try to question and dissolve what seems to be taken for granted and instead look at occurrences with 
fresh eyes and from a perspective of a stranger (Spindler, 1982). The ethnographic stance is an attempt at seeing things for what they 'really' are, by overcoming and avoiding superstitions. The aim of reaching ethnographic understanding of everyday knowledge relies on doing research with the informants or participants. This calls for an interpretive, creative and thoughtful approach, not far from other approaches such as arts-based research, where data collection, analysis and reporting are intertwined (Sivenius \& Friman, 2017). As we have shown above, this is not an unproblematic process.

The field of adult education practices is broad and action-oriented. This field can be studied as learning environments, situations and encounters, unfolding as the research is carried out. This provides a fruitful field for ethnographic approaches for example to capture and consider the broader and societal significances of adult education and learning taking place in everyday life and en passant.

How then should qualitative ethnographic research be done? For example, how should the ethnographer avoid influencing the studied group too much or too little? The critical ethnographer has to consider issues regarding understanding and interpretations, as has been discussed in this chapter. Generally, understanding and interpretations affect both the informants and the researcher. At best, the attentive ethnographer sees behind both situations and words, as it were, inside the collective. The ethnographer regards the possibility of things being quite different to what the interviewees for example are portraying. Observations might reveal such contradictions. However, the ethnographer's own personal history and presumptions are unavoidably part of for example writing the fieldnotes, coding these initial observations and analyzing them. This cannot be escaped, but has to be recognized and considered in the search for truthfulness.

\section{REFERENCES}

Andersson, E., \& Laginder, A.-M. (2013). Dimensions of power: The influence of study circles. In A.-M. Laginder, H. Nordvall, \& J. Crowther (Ed.), Popular education, power and democracy. Swedish experiences and contributions (pp. 99-121). Leicester: NIACE.

Bagnall, R. G. (2010). Citizenship and belonging as a moral imperative for lifelong learning. International Journal of Lifelong Education, 29(4), 449-460. doi:10.1080/02601370.2010.488812

Bauman, Z. (1999). In search of politics. Cambridge: Polity Press.

Biesta, G. (2011). Learning democracy in school and society. Education, lifelong learning, and the politics of citizenship. Rotterdam, The Netherlands: Sense Publishers.

Brewer, J. (2000). Ethnography. Buckingham: Open University Press.

Cohen, L., Manion, L., \& Morrison, K. (2002). Research methods in education. London: Routledge Falmer.

Davies, C. A. (2002). Reflexive ethnography. A guide to researching selves and others. London: Routledge.

Emerson, R. M., Fretz, R. I., \& Shaw, L. L. (2001). Participant observation and fieldnotes. In P. Atkinson, A. Coffey, S. Delamont, J. Lofland, \& L. Lofland (Eds.), Handbook of ethnography (pp. 352-368). London: Sage Publications.

Folkbildningsrådet. (2018) Fakta om folkbildning. Stockholm: Folkbildningsrådet. Retrieved June 18, 2018, from http://www.folkbildningsradet.se/globalassets/fakta-om-folkbildning/fbr_fickfakta2017 webb.pdf 


\section{A. PASTUHOV \& A. SIVENIUS}

Geertz, C. (1973). The interpretation of cultures. New York, NY: Basic Books.

Gordon, T., Holland, J., \& Lahelma, E. (2001). Ethnographic research in educational settings. In P. Atkinson, A. Coffey, S. Delamont, J. Lofland, \& L. Lofland (Eds.), Handbook of ethnography (pp. 188-203). London: Sage Publications.

Hammersley, M., \& Atkinson, P. (2007). Ethnography. Principles in practice (3rd ed.). London \& New York, NY: Routledge.

Harding, T. (2011). Learning democracy in a Swedish gamers' association: Representative democracy as experiential knowledge in a liquid civil society. European Journal for Research on the Education and Learning of Adults, 2(2), 135-149. https://doi.org/10.338/rela.2000-7426.rela0042

Laginder, A.-M., Nordvall, H., \& Crowther, J. (2013). Introduction. In A.-M. Laginder, H. Nordvall, \& J. Crowther (Eds.), Popular education, power and democracy. Swedish experiences and contributions (pp. 3-13). Leicester: NIACE.

Larsson, S. (2001). Seven aspects of democracy as related to study circles. International Journal of Lifelong Education, 20(3), 199-217. doi:10.1080/02601370110036073

Larsson, S., \& Nordvall, H. (2010). Study circles in Sweden. An overview with a bibliography of international literature. Linköping: Linköping University Electronic Press.

May, T. (1993). Social research: Issues, methods and processes. Buckingham: Open University Press.

Pastuhov, A. (2018). Att vara och agera medborgare. En etnografisk studie i folkbildande praktiker. (Diss.) Åbo: Åbo Akademi.

Pastuhov, A., \& Rusk, F. (2017). Citizenship as individual responsibility through personal investment An ethnographic study in a study circle. RELA - European Journal for Research on the Education and Learning of Adults, 9(1), 95-108. https://doi.org/10.3384/rela.2000-7426.relaojs99

Pole, C., \& Morrison, M. (2003). Ethnography for education. Maidenhead: Open University Press.

SCB. (2018). Summary of population statistics 1960-2017. Retrieved June 18, 2018, from https://www.scb.se/en/finding-statistics/statistics-by-subject-area/population/populationcomposition/population-statistics/pong/tables-and-graphs/yearly-statistics--the-whole-country/ summary-of-population-statistics/

Sivenius, A., \& Friman, I. (2017). An art-based project as a research approach - Young people's lives in pictures and words. The Finnish Journal of Youth Research, 35(1-2), 26-38.

Spindler, G. (1982). General introduction. In G. Spindler (Ed.), Doing the ethnography of schooling: Educational anthropology in action (pp. 1-13). New York, NY: Holt, Rinehart and Winston.

Tøsse, S. (2009). Folkbildning som universellt fenomen. Om betydelser och motsvarigheter i historiskt och internationellt perspektiv. Linköping: Mimer.

Weisner, T. S. (1996). Why ethnography should be the most important method in the study of human development. In R. Jessor, A. Colby, \& R. A. Shweder (Eds.), The John D. and Catherine T. MacArthur foundation series on mental health and development. Ethnography and human development: Context and meaning in social inquiry (pp. 305-324). Chicago, IL: University of Chicago Press.

Wolcott, H. F. (1981). Home and away: Personal contrasts in ethnographic style. In D. A. Messerschmidt (Ed.), Anthropologists at home in North America: Methods and issues in the study of one's own society (pp. 255-265). New York, NY: Cambridge University Press. 